\title{
Clozapine induced severe weight loss in resistant schizo- phrenia managed with risperidone add-on therapy
}

\author{
M Chandradasa, CS Kuruppuarachchi, LC Rathnayake, KALA Kuruppuarachchi
}

\section{Abstract}

Clozapine is prescribed for resistant schizophrenia. It is usually associated with weight gain. There have been only a few reports of weight loss associated with clozapine treatment and we report two patients from Sri Lanka. The first patient lost $27 \%$ of bodyweight on clozapine while the second lost $17 \%$. Both were clinically stable on clozapine, with marked reduction of psychotic symptoms. Adding risperidone helped to regain the lost weight in the described patients.

Key words: clozapine, weight, schizophrenia, Sri Lanka

SL J Psychiatry 2020; 11(2): 38-39

\section{Background}

Clozapine has a significant propensity to cause weight gain, which is considered to be a serotonergic response and is also associated with metabolic syndrome (1). The reasons for increased weight gain, obesity and resulting medical complications are multifactorial and include lifestyle factors, treatment-related factors and genetic factors (1). Clozapine induced weight loss has been reported previously from Sri Lanka and other countries $(2,3)$. The mechanisms underlying weight loss are likely to be environmental, genetic and may also be related to the reduction of negative symptoms and satisfactory adherence to diet and exercise. Risperidone, which is a second-generation antipsychotic, has been safely combined with clozapine in previous case reports with an adverse event profile for clozapine/risperidone treatment similar to that for clozapine/placebo (4). We report the following case histories to highlight the clozapineinduced weight loss, and weight gain after adding risperidone. Written informed consent was obtained from the two patients.

\section{Case Report 1}

The first patient is a female in her late twenties diagnosed with resistant schizophrenia. She had been clinically stable for nearly two years on clozapine, with a reduction of positive symptoms. Her psychotic symptoms had resolved with treatment with clozapine $200 \mathrm{mg}$ daily. The psychiatrist noticed that she has been gradually losing weight over the last year without a change in appetite. She had lost $12 \mathrm{kgs}$ (27\%) of body weight, resulting in her body mass index being in the underweight range (her initial weight was $45 \mathrm{kgs}$ ). Her haematological, biochemical and radiological investigations were normal. No other cause for the weight loss could be found. She experienced a $1 \mathrm{~kg}$ weight gain two weeks after starting risperidone $1 \mathrm{mg}$ nocte, while continuing clozapine. The risperidone dose was increased to $2 \mathrm{mg}$ daily and after three months her weight increased to 40 kgs from 33 kgs. After combined clozapine and risperidone treatment for six months, she regained her previous weight of $45 \mathrm{kgs}$ and remained in the same weight 12 months later.

\section{Case Report 2}

The second person is a male in his early forties diagnosed to have resistant schizophrenia, who was on treatment with clozapine $300 \mathrm{mg}$ daily. He had been clinically stable on this dose. However, it was noticed that he has been losing weight despite having his usual appetite. He had lost $10 \mathrm{kgs}$ (17\% of his body weight) over six months (from his original weight of $60 \mathrm{~kg}$ ), and as a result, he became underweight, with a below normal body mass index. All haematological, biochemical and radiological investigations were normal. He was then commenced on risperidone $1 \mathrm{mg}$ daily in addition to clozapine. This was followed by a 2 kgs weight gain over the next two months, and risperidone was continued at $2 \mathrm{mg}$ daily. He showed a notable response and a further six kilograms over five months, and his weight remained stable at 12 months.

\section{Discussion}

Clozapine is known to be associated with weight gain, but here we describe two patients with significant weight 
loss. In the past, weight loss associated with clozapine use has been attributed to improved mental state, better adverse-effect management and engagement in dietary practices and regular exercise (5). However, there is literature reporting weight loss early during clozapine treatment, associated with poor response to treatment (6). In contrast, the patients who lost weight in this case report had responded well clinically to clozapine and their positive symptoms had reduced markedly with treatment.

Clozapine is a second-generation antipsychotic, with affinity to dopamine, serotonin, muscarinic, histamine, adrenergic, GABAergic and glutamatergic receptors (7). This multi-receptor profile of clozapine is thought to be related to its unique efficacy and potential to cause either weight gain or weight loss. Strong antagonist activity at $\mathrm{D}_{2}, \mathrm{M}_{3}, \mathrm{H}_{1}$ and $5 \mathrm{HT}_{2 \mathrm{C}}$ receptors is seen with clozapine and is likely to be related to the significant weight gain (7-8).

Why clozapine should cause weight gain is not understood. Other factors, such as genetic variations may play a role. A certain genetic type of $5 \mathrm{HT}_{2 \mathrm{C}}$ receptor labelled as - $759 \mathrm{C} / \mathrm{T}$, $\mathrm{T}$ allele rather than $\mathrm{C}$ allele has shown to protect against antipsychotic-induced weight gain and may be related to the weight loss in our patients (9). Blocking $D_{2}$ receptors can cause weight gain, and adding risperidone to clozapine may have caused increased weight through this mechanism (2). Antipsychotic induced weight gain is problematic for many patients, but was used in our two patients to restore body weight to normal levels. Risperidone is known to cause less weight gain compared to olanzapine, but causes more weight gain than amisulpride (10). Risperidone was selected for add-on therapy in both patients due to it being potentially able to cause weight gain, it's availability in the state health sector, and relatively less sedative adverse effect profile, as both patients were currently employed and were already on clozapine.

Our case report demonstrates the use of adding a lowdose antipsychotic such as risperidone to the existing clozapine regime, in patients who had experienced significant weight loss with clozapine. Future studies should explore the pharmacogenetic basis of antipsychotic-induced weight loss.

\section{Statement of contribution}

MC was involved in the design of the study and writing of the manuscript. CSK was responsible for the literature review. LCR supported the writing of the manuscript and was responsible for the final version. KALAK was responsible for the concept of the publication and writing of the manuscript.

\section{Declaration of interests}

None declared.
M Chandradasa, KALA Kuruppuarachchi, Department of Psychiatry, Faculty of Medicine, University of Kelaniya, Ragama, and Colombo North Teaching Hospital, Ragama, Sri Lanka

CS Kuruppuarachchi, General Sir John Kotelawala Defence University, Colombo, Sri Lanka

LC Rathnayake, National Institute of Mental Health, Angoda, Sri Lanka

Corresponding author: M Chandradasa

Email:miyuruc@kln.ac.lk

http://orcid.org/0000-0002-1873-8228

\section{References}

1. Gressier F, Porcelli S, Calati R, Serretti A. Pharmacogenetics of clozapine response and induced weight gain: a comprehensive review and meta-analysis. European Neuropsychopharmacology. 2016; 26(2): 163-85.

2. Tungaraza TE. Significant weight loss following clozapine use, how is it possible? A case report and review of published cases and literature relevant to the subject. Therapeutic Advances in Psychopharmacology. 2016; 6(5): 335-42.

3. Hanwella R, De Silva V, Wijeratne C, Ketharanathan T, De Silva J. Clozapine-associated weight loss. Journal of Psychopharmacology. 2010; 24(7): 1127-9.

4. Josiassen RC, Joseph A, Kohegyi E, Stokes S, Dadvand M, Paing WW, Shaughnessy RA. Clozapine augmented with risperidone in the treatment of schizophrenia: a randomized, double-blind, placebo-controlled trial. Am J Psychiatry. 2005; 162(1): 130-6.

5. Appiani F, Carroll BT, Muñoz C, Trecco J. Clozapineinduced weight loss. Annals of clinical psychiatry: official journal of the American Academy of Clinical Psychiatrists. 2011; 23(3): 225.

6. Thomas N, Ravan J, Jebaraj P, Braganza D. Clozapine producing weight loss: A case series with possible clinical implications-A hypothesis. Journal of postgraduate medicine. 2009; 55(4): 317.

7. Wenthur CJ, Lindsley CW. Classics in Chemical Neuroscience: Clozapine. ACS Chemical Neuroscience. 2013; 4(7): 1018

8. Reynolds GP, Kirk SL. Metabolic side effects of antipsychotic drug treatment-pharmacological mechanisms. Pharmacology \& therapeutics. 2010; 125(1): 169-79.

9. Wallace TJ, Zai CC, Brandl EJ, Müller DJ. Role of 5HT2C receptor gene variants in antipsychotic-induced weight gain. Pharmacogenomics and Personalized Medicine. 2011; 4: 83.

10. Rummel-Kluge C, Komossa K, Schwarz S, Hunger H, Schmid F, Lobos CA, Kissling W, Davis JM, Leucht S. Head-to-head comparisons of metabolic side effects of second-generation antipsychotics in the treatment of schizophrenia: a systematic review and meta-analysis. Schizophr Res 2010; 123(2-3): 225-33. 